\title{
Lewis and ABH Substances in Amniotic Fluid Obtained by Amniocentesis
}

\author{
Minerva B. Argilla ${ }^{[18]}$ and Phillip Sturgeon \\ Gwynne Hazen Cherry Memorial Laboratories, Department of Pediatrics, Hematology Division, University of California at Los Angeles \\ School of Medicine, Los Angeles, California, USA
}

\begin{abstract}
Extract
When eight amniotic fluid samples obtained by transabdominal amniocentesis at various ages of gestation (15-38 weeks) were tested, Lewis substances were present in considerable concentration as early as 15 weeks of gestation. The amniotic Lewis substances found corresponded to the Lewis and secretor phenotypes of the fetus ascertained by determination of the erythrocyte and salivary phenotypes of the motherinfant pairs after delivery. These findings indicate strongly that the amniotic Lewis substances are exclusively of fetal origin. Although not conclusive, the data also indicate that the amniotic $\mathrm{ABH}$ substances are the expression of the fetal $\mathrm{ABH}$ and secretor status.
\end{abstract}

\section{Speculation}

This preliminary study shows that the fetal Lewis and secretor phenotype can be determined antenatally by amniocentesis. This information could be clinically significant in the prenatal detection of hereditary conditions exhibiting linkage to the Lewis and secretor loci. In further research on this subject, Lewis phenotypes of erythrocytes in infants should be determined at appropriate postnatal age with due consideration for the maturation process and differential tissue expressivity of the Lewis and secretor gene systems. Amniotic fluid samples should be obtained preferably by transabdominal amniocentesis to avoid contamination by maternal secretions and saliva from infants should be obtained several days postnatally.

\section{Introduction}

Although the soluble blood group substances A, B, and $\mathrm{H}$ are known to be present in amniotic fluid at the time of delivery $[4,6,10]$ and as early as 9-24 weeks of gestation [5], the presence of Lewis substances in amniotic fluid at any stage of pregnancy has not been previously studied. In this report, we present our results from semiquantitative measurements of Lewis substances $\mathrm{Le}^{\mathrm{a}}, \mathrm{Le}^{\mathrm{b}}$, and $\mathrm{Le}^{\mathrm{x}}$ and of $\mathrm{ABH}$ in amniotic fluid obtained by amniocentesis at different stages of gestation. To determine accurately the phenotypes of the mother and infant pairs, we tested the paired sub- jects several months after delivery for their $\mathrm{ABH}$, Lewis, and secretor types; these have been compared with our data on amniotic fluid.

\section{Materials and Methods}

Eight women, who had transabdominal amniocentesis, and their infants were studied. Amniocentesis was done in three at $15-16$ weeks of gestation primarily for chromosomal analysis. In two, the procedure was done at 29-30 weeks of gestation to monitor the degree of $\mathrm{Rh}$ sensitization, and in three, it was done at 36-38 weeks of gestation to determine fetal maturity prior to induc- 
Table I. Summary of mother-infant pairs studied showing blood, saliva, and amniotic fluid, and ABO, Lewis, and secretor types ${ }^{1}$

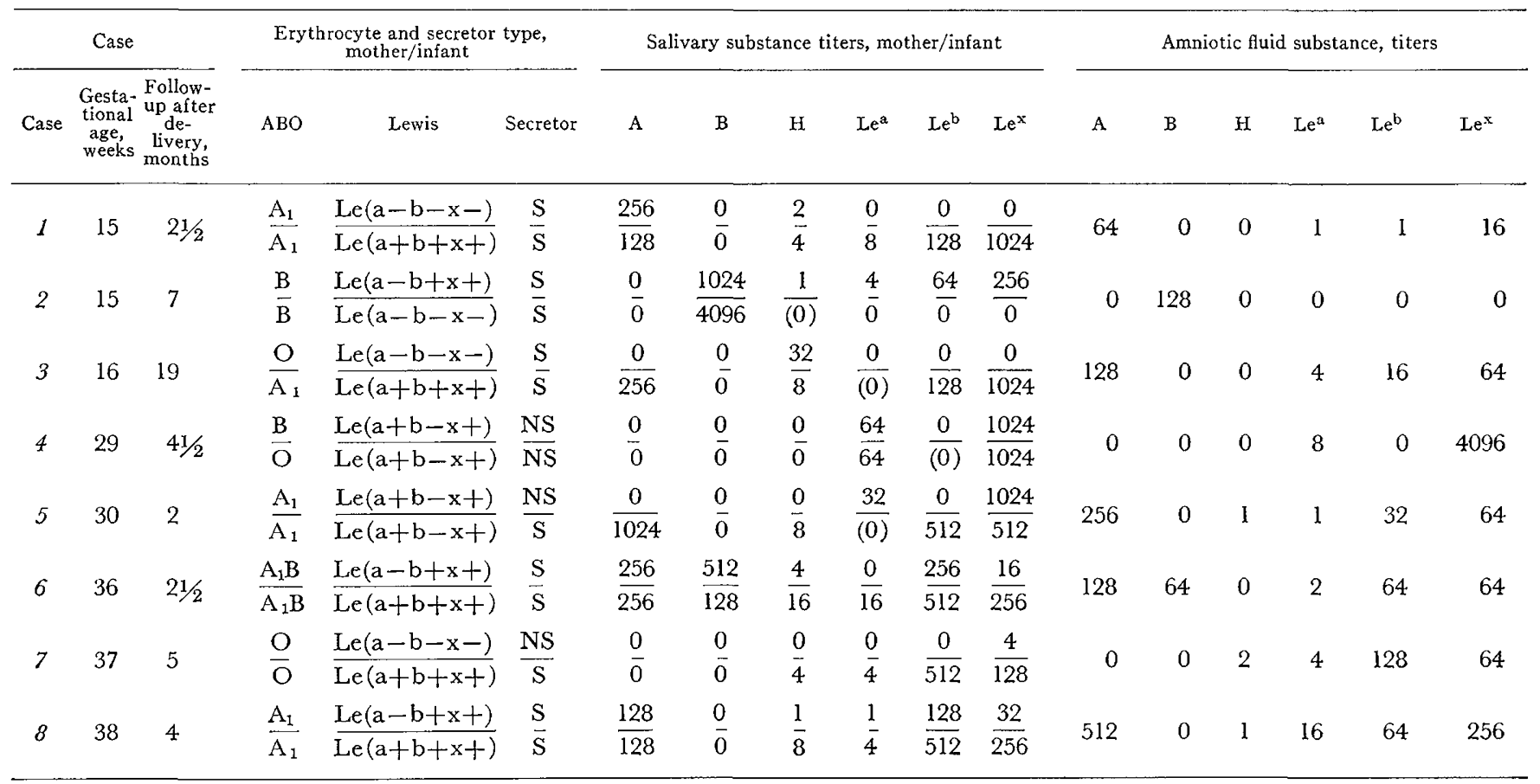

$1(0)$ : Partial inhibition by the undiluted saliva.

tion of labor. All eight mother-infants pairs were subsequently studied for 2-19 months after delivery by tests on both blood and saliva. All amniotic fluid samples were free of gross blood or hemolysis; samples were kept at $-20^{\circ}$ until tested. All samples were centrifuged and the supernatants were used for inhibition studies.

$\mathrm{Le}^{\mathrm{a}}, \mathrm{Le}^{\mathrm{b}}, \mathrm{Le}^{\mathrm{x}}$, and $\mathrm{ABH}$ substances in both amniotic fluid and saliva were titrated by inhibition of hemagglutination through the use of the reagent antisera and methods described previously [14]. A preliminary test was made of all samples to rule out any agglutinating activity against the test cells used in the inhibition titrations. Rh-negative cells were used in testing the amniotic fluids from the Rh-sensitized women. The reciprocal of the highest dilution of the amniotic fluid or saliva which completely inhibited the hemagglutination system was taken as the titer of substance in the sample. Erythrocytes were tested for $\mathrm{ABH}, \mathrm{Le}^{\mathrm{a}}, \mathrm{Le}^{\mathrm{b}}$, and $\mathrm{Le}^{\mathrm{x}}$ antigens using the reagent antisera and methods described previously [14].

\section{Results}

\section{Lewis Substances in Amniotic Fluid}

Except in one case in which the fetus was erythrocyte type $\operatorname{Le}(a-b-x-)$ (case 2), Lewis substances were present in good titers in all of the amniotic fluid samples; they were demonstrable as early as 15-weeks of gestation (Table I). In three cases (case 1, 3, and 7) in which the mothers were erythrocyte type Le $(a-b-x-)$ and had no detectable salivary Lewis substances, the amniotic fluids contained substantial quantities of $\mathrm{Le}^{\mathrm{a}}, \mathrm{Le}^{\mathrm{b}}$, and Le $\mathrm{e}^{\mathrm{x}}$ substances; these corresponded to postnatal erythrocyte and salivary Lewis phenotypes in the infants. Therefore in these three cases, the Lewis substance could only have been of fetal origin. On the other hand, in case 2 in which the infant at 7 months postnatal age was erythrocyte and saliva type Le $(a-b-x-)$ and the mother was erythrocyte type $\mathrm{Le}(\mathrm{a}-\mathrm{b}+\mathrm{x}+)$ with salivary $\mathrm{Le}^{\mathrm{a}}, \mathrm{Le}^{\mathrm{b}}$, and $\mathrm{Le}^{\mathrm{x}}$ substances, the amniotic fluid was completely devoid of Lewis substances. In this case, maternal contribution of Lewis activity to the amniotic fluid did not occur. A large number of pairings like the latter would have to be studied to show that this is the rule.

In case $5, \mathrm{Le}^{\mathrm{b}}$ was found in the amniotic fluid at 30 weeks of gestation although both the mother and her infant, when typed 2 months after delivery, were erythrocyte type $\operatorname{Le}(a+b-x+)$. The saliva of this infant, however, showed not only the expected $\mathrm{Le}^{\mathrm{a}}$ and Le $e^{x}$ substances, but also a substantial titer of $\mathrm{Le}^{\mathrm{b}}, \mathrm{A}$, and $\mathrm{H}$ substances. These findings demonstrate clearly that the genotype of the infant included both a Lewis 
and a secretor gene. The amniotic $\mathrm{Le}^{\mathrm{b}}$ substance in this case must necessarily have been of fetal origin since this antigen was entirely lacking in the erythrocytes and saliva of the mother. The absence of the expected $\mathrm{Le}^{\mathrm{b}}$ antigen in the erythrocytes of this infant who was Lewis-positive, secretor at 2 months of age is consistent with the fact that expression of the secretor gene in erythrocytes (as manifested by their becoming $\mathrm{Le}^{b}$ positive) develops slowly after birth, usually becoming evident between the first week and fourth month of postnatal life [14]. The salivary expression of the Lewis-secretor genes, on the other hand, is fully developed at birth [14]; hence their prenatal expression in the amniotic fluid is not unexpected. It is evident in this case that the only secretor gene influencing the conversion of the amniotic Le $\mathrm{Le}^{\mathrm{a}}$ to $\mathrm{Le}^{\mathrm{b}}$ substance was that of the infant.

The amniotic fluid in case 4 was obtained at 29 weeks of gestation from the only infant in the study who was Lewis-positive, nonsecretor. The remarkably high titer of 4.096 of Le ${ }^{\mathrm{x}}$ substance is higher than that observed in any other subject in this study or in the saliva of normal Lewis-positive subjects whom we have tested $[2,14]$. That the Le ${ }^{\mathrm{x}}$-inhibiting activity of this amniotic fluid is not a manifestation of "cross reactivity" with anti-Lea is shown by the marked difference between the titers of the two substances; the Le $\mathrm{e}^{\mathrm{a}}$ titer was only 8 .

\section{ABH Substances in the Amniotic Fluid}

Except in one nonsecretor pair, case 4, all of the amniotic fluids showed considerable $\mathrm{ABH}$ activity. In six cases (cases 1, 2, 5, 6, 7, and 8), in which the mothers and the infants had the same $\mathrm{ABO}$ blood type and at least one member of the pair was a secretor, it could not be determined whether the amniotic $\mathrm{ABH}$ substances were of fetal and/or of maternal origin. Only in the remaining case (case 3) (the blood of the mother was type $O$ and that of the infant was type $A$; both were secretors) could the question be studied. The amniotic A substance had to be of fetal origin. A series of reciprocal type of $\mathrm{ABO}$-heterospecific pregnancies, such as $\mathrm{A}$ or $\mathrm{B}$ mother $\times \mathrm{O}$ infant, would have to be studied to show whether or not there is a regular maternal contribution to the $\mathrm{A}$ or $\mathrm{B}$ phenotype of amniotic fluid. However, the known biochemical composition and molecular size of both substances [16] and extrapolation from our Lewis data preclude any sound reason to anticipate a maternal contribution to the $\mathrm{ABH}$ phenotype of amniotic fluid if there is none to the Lewis phenotype.

\section{Source of Influence of Secretor Gene on Amniotic Fluid}

In two cases (cases 5 and 7 ), the mothers were nonsecretors of $\mathrm{ABH}$ substances and the infants were secretors. Both pairs were of the same $\mathrm{ABO}$ type and the amniotic fluid showed blood group substances appropriate to both mothers and infants. These findings show that, in the presence of a fetal secretor gene, $\mathrm{ABH}$ substances may be found in the amniotic fluid independent of the secretor status of the mother. Case 4 is an example of a type $\mathrm{O}$ nonsecretor $\times \mathrm{O}$ nonsecretor pairing; as would be expected, no $\mathrm{H}$ substance was present in the amniotic fluid. However, since both were Lewis positive, the expected Lewis substances were found. We did not have heterospecific pregnancies reciprocal to cases 5 and 7 (secretor mothers $\times$ nonsecretor infants). Judging from our example involving the Lewis sytem, it appears unlikely that a maternal secretor gene could activate the expression of a fetal $\mathrm{A}, \mathrm{B}$, or $\mathrm{H}$ gene in the nonsecretor infant.

\section{Discussion}

It is clear from the data presented that Lewis substances are present in amniotic fluid in substantial titers and that they are present as early as 15-weeks gestation, as in the case of $\mathrm{ABH}$ substances. Furthermore, the data indicate that the source of the Lewis amniotic fluid blood group substances is fetal only. Three possible mechanisms could be involved in the elaboration of amniotic Lewis as well as $\mathrm{ABH}$ substance. (1) $\mathrm{It}$ is exclusively the expression of the fetal $\mathrm{ABH}$, secretor, and Lewis genotype (mechanism preferred by us); (2) it is exclusively the expression of maternal $\mathrm{ABH}$, secretor, and Lewis genotype and (3), it is the product of the interaction or combinations of the fetal and maternal $\mathrm{ABH}$, secretor, and Lewis genotypes acting on the amniotic fluid from both directions.

In the three mother-infant pairings in which the mothers were Lewis negative (lele) with infants who were Lewis positive (Le/), Lewis substances were present in the amniotic fluid; these substances therefore had to be exclusively fetal in origin. In one mother-infant pair in which the mother was Lewis positive (Le/) and her infant was Lewis negative (lele), no amniotic Lewis substance was present. If the presence of Lewis substances in the amniotic fluid is exclusively dependent on the maternal Lewis genotype, Lewis substances should have been present in the amniotic fluid of the infant who was Lewis negative. Our one case is not sufficient to completely exclude the possibility of any 
maternal contribution to the final composition of the amniotic fluid, but there is no evidence for such a contribution at present.

Our data on the ABH substances in the amniotic fluid are limited by the small number of $\mathrm{ABO}$ heterospecific mother-infant pairs. One case of $O$ mother $\times A$ infant showing $\mathrm{A}$ substance in the amniotic fluid indicates clearly that maternal $\mathrm{ABH}$ genes and/or substances are not necessary for the appearance of $\mathrm{ABH}$ substances in the amniotic fluid. A significant series of A mother $\times \mathrm{O}$ infant pairings in which both were secretors, showing the absence of $\mathrm{A}$ substance, would prove the converse; that is, $\mathrm{ABH}$ substances in the amniotic fluid are not influenced by the maternal ABO type.

In the two nonsecretor mother $\times$ secretor infant pairings, $\mathrm{ABH}$ substances were found in the amniotic fluid. This demonstrates that the secretor gene of the infant can be expressed in the amniotic fluid regardless of secretor type of the mother. In both of these cases, $\mathrm{Le} \mathrm{e}^{\mathbf{b}}$ substance was also found; this indicates that the action of the secretor gene on the Lewis system is also expressed prenatally in the amniotic fluid. Our data are again limited by the scarcity of infants who are nonsecretors. The consistent absence of amniotic $\mathrm{ABH}$ substances in secretor mother $\times$ nonsecretor infant pairs would be necessary to prove that only the secretor status of the infant, and not that of the mother, determines the expression of $\mathrm{ABH}$ substances in the amniotic fluid.

Previous reports on $\mathrm{ABH}$ substances in amniotic fluid have shown conflicting and confusing results. Several found that the amniotic $\mathrm{ABH}$ blood group activity reflected only the $\mathrm{ABO}$ blood type of the fetus $[3,5$, 10]. Harper et al. [5] tested amniotic fluids obtained during therapeutic abortions between 9 and 24 weeks of gestation. They reported that $\mathrm{ABH}$ substances of fetal origin were present in fetuses who were secretors and that the presence or absence of the substances was not dependent on secretor status of the mother or related to $\mathrm{ABO}$ type of the mother. Because of the nature of their study, direct correlation between the secretor status of the aborted fetuses and the $\mathrm{ABH}$ substances found in amniotic fluid was not possible. Przestwor [9] and Turowska and Bromboszcz [15] have also reported that the amniotic $\mathrm{ABH}$ substances obtained at term correlated with the secretor status of the fetus.

That there was possible maternal contribution to the $\mathrm{ABH}$ blood group activity of the amniotic fluid in some cases have been reported [4, 6, 7]. Freda [4] found in his study that only when the mother was a secretor could her blood group substances be found in the amniotic fluid. Hostrup [6] reported maternal blood group substances in the amniotic fluid of some mothers who were secretors but not in all cases, and thus suggested that the presence of maternal blood group substances could have been due to contamination of the amniotic fluid during sampling. Both Freda [4] and Hostrup [6] found ABH substances in the amniotic fluids of both secretor and nonsecretor infants; however, the concentration was higher among their infants who were secretors. In Hostrup's study [6], this was true for all his cases of ABO-homospecific motherinfant pairings in which at least one of the pair was a secretor. As pointed out earlier, in ABO-homospecific mother-infant pairs in which both are secretors, there is no way to determine whether the $\mathrm{ABH}$ blood group substance present in amniotic fluid is fetal and/or maternal in origin. However, in cases of mother (nonsecretor) $\times$ infant (secretor) pairings, the $\mathrm{ABH}$ blood group substances could only be the expression of the secretor gene of the fetus. In mother (secretor) $x$ infant (nonsecretor) pairings, the presence of amniotic $\mathrm{ABH}$ substances in much lower concentration than that in infants who are secretors could be explained by either contamination of the amniotic fluid with uterine secretions or by transplacental passage of $\mathrm{ABH}$ substances from the mother into the fetal environment. The known high molecular weight of blood group substances [16] makes the latter explanation improbable.

Another possible but highly speculative explanation is that $\mathrm{ABH}$ substances found in the amniotic fluid of infants who are nonsecretors could be the expression of an interaction of the secretor gene products of the mother with precursor blood group substances of the fetus present in the amniotic fluid. This would convert precursor to $\mathrm{A}, \mathrm{B}$, or $\mathrm{H}$ substances, which makes the fetus which is genetically a nonsecretor express itself in utero as a secretor.

Part of the difficulty in studies showing a maternal contribution to amniotic fluid could be related to the sensitivity of the methods used in both qualitative and quantitative tests; test systems that are too sensitive have the possibility of giving false positive results. Another and more likely source for the conflicting results could be from the different methods of collecting amniotic fluid. Most of the samples in the previous studies were obtained by transvaginal puncture of the intact amniotic membrane during labor $[3,4,6,10]$ and a few were obtained by direct puncture of the uterus during delivery by Caesarian section [6]. There was always a possibility of contamination by maternal blood and/or uterine secretions.

In the light of the findings presented here and the 
conflicting results of previous studies, the need for additional critical studies is evident. Now that transabdominal amniocentesis is possible with little risk to mother and fetus and with the least chance of contamination by maternal secretions, it is the preferred method of collection.

Inasmuch as the secretor status of the fetus probably plays a critical role in the final composition of amniotic blood group substances, an accurate method of determining this character should be used in further investigations of maternal versus fetal contribution. There are two ways by which this can be done. The most direct and commonly used is to test for salivary $\mathrm{ABH}$ substances. Although this can be done in the immediate newborn period, it is preferably done later in the neonatal period when technically it is easier to collect saliva which is free from contamination by secretions from the mother and is in sufficient quantities for quantitative tests. A method which is indirect but just as reliable is to test erythrocytes for the Lewis ${ }^{b}$ antigen. The Lewis gene is present in about $93 \%$ of European populations [8], and when a secretor gene is present, the erythrocytes of adults will be Le $\mathrm{L}^{b}$ positive. However, in infants and children younger than 2 years of age, Lewis typing of erythrocytes is not a reliable method for determining the secretor status since both the expression of the Lewis and secretor character undergo a maturation process [14]. The Le antigen, which is one of the expressions of the Lewis gene, is usually demonstrable within the first week of life [1]. The Le ${ }^{b}$ antigen, however (which is the expression of the secretor gene in the Lewis-positive infant), may not be evident until 2 weeks to 4 months of postnatal life. Le $\mathrm{e}^{\mathrm{x}}$, another expression of the Lewis gene, may be its only manifestation in erythrocytes in the immediate newborn period [14]. In determining the Lewis status by salivary test, caution should also be exercised since Lewis-negative individuals can show small traces of salivary Lewis substances [2]; however, quantitative tests can clearly distinguish the two classes in older children and adults. Previous publication from these laboratories listed a case of an infant who was a Lewisnegative secretor with substantial salivary titers of $\mathrm{Le}^{\mathrm{a}}$ and $\mathrm{Le}^{\mathrm{b}}$ substances in the newborn period [1].

From these studies it appears highly probably that fetal $\mathrm{ABH}$, secretor and Lewis type can be determined antenatally from amniotic fluid. Inasmuch as linkage to the $\mathrm{ABO}$ locus is known to exist in the nail-patella syndrome [13], and recent studies have shown the possible linkage of the locus for myotonic muscular dystrophy to the secretor locus $[11,12]$, these determinations could be of clinical value.

\section{Conclusion}

Lewis blood group substances, as is the known case for $\mathrm{ABH}$ substances, are present in amniotic fluid. With the use of qualitative and semiquantitative serological techniques to study amniotic fluid obtained intrapartum by transabdominal amniocentesis, we have shown that these substances are present in substantial titers as early as 15 weeks of gestation. In the case of the Lewis system, our data indicate strongly that these substances are exclusively of fetal origin. Although the mother-infant pairs studied did not permit as critical evaluation of the source of amniotic ABH substances, the data are also consistent with the interpretation that the amniotic $\mathrm{ABH}$ substances are exclusively of fetal origin. The latter is in agreement with several previous reports and is inconsistent only with those reports in which there existed a risk of contamination of the amniotic fluid samples by maternal secretions. After testing for Lewis as well as $\mathrm{ABH}$ substances in amniotic fluid, it appears highly probable that the phenotypic expression of fetal $\mathrm{ABH}$, Lewis, and secretor systems can be ascertained antenatally. This information could be clinically significant in the prenatal detection of hereditary conditions exhibiting linkage to the $\mathrm{ABH}$, Lewis, and secretor systems.

In further research in this subject, Lewis phenotypes in erythrocytes of infants should be determined at postnatal age with due allowance for maturation and differential tissue expressivity of the Lewis and secretor gene systems. Also, to avoid contamination of specimens by maternal secretions, amniotic fluid should be obtained by transabdominal amniocentesis and saliva from infants should be obtained several days postnatally.

\section{References and Notes}

1. Arcilla, M. B., ANd Sturgron, P.: Perinatal expression of the Lewis and secretor blood group systems. Proceedings of the XIIIth International Congress of Pediatrics, Vienna, Vol. VII, p. 79. Vexlag dex Wiener Medizinischen Akademie, Vienna (1971).

2. Arcilla, M. B., And Sturgeon, P.: Studies on the secretion of blood group substances. II. Observations on the red cell phenotype Le $(\mathrm{a}-\mathrm{b}-\mathrm{x}-)$ (In preparation).

3. Buchanan, D. J., and Raporort, S.: Composition of meconium: serological study of blood-group-specific substances found in individual meconiums. Proc. Soc. Exp. Biol. Med., 77: $114(1951)$.

4. FREDA, V. J.: A-B-O(H) blood group substances in the human maternal-fetal barrier and amniotic fluid. Amer. J. Obstct. Gynecol., 76: 407 (1958).

5. Harper, P., Bias, W. B., Hurchinson, J. R., and McKusick, V. A.: ABH secretor status of the fetus: a genetic marker identifiable by amniocentesis. J. Med. Genet., 8: 438 (1971). 
6. Hostrup, H.: Influence of foetal $A$ and $B$ blood-group substances on the immunization of pregnant women. Vox Sang., 9: 301 (1964).

7. Kabat, E. A., Bendich, A., Bezer, A. E., And Beiser, S. M.: Inmunochemical studies on blood groups. IV. Preparation of blood group A substances from human sources and a comparison of their chemical and immunochemical properties with those of the blood group A substance from hog stomach. J. Exp. Med., 85: 685 (1947).

8. Molluson, P. L.: Blood Transfusion in Clinical Medicine, Ed. 4, p. 273. (Davis, Philadelphia, 1967).

9. Przestwor, E.: Cited by Harper et al. [5]: ABH secretor status of the fetus: a genetic marker identifiable by aminocentesis. J. Med. Genet., 8: 438 (1971).

10. PUTKONEN, T.: Uber die gruppenspezifischen eigenschaften verschiedener korper flussigkeiten. Acta Soc. Med. Fenn. Duodecim Series A (Helsinki), 14: 113 (1930).

11. RenwiCK, J. H. AND Bolling, D. R.: An analysis procedure illustrated on a triple linkage of use for prenatal diagnosis of myotonic dystrophy. J. Med. Genet, 8: 399 (1971).

12. Renwick, J. H., Bundey, S. E., Ferguson-Smith, M. A., AND IZATT, M. M.: Confirmation of linkage of the loci for myotonic dystrophy and ABH secretion. J. Med. Genet., 8: 407 (1971).
13. Renwick, J. H., AND LAWLER, S. D.: Genetical linkage between the $\mathrm{ABO}$ and nail-patella loci. Ann. Hum. Genet., 19: $312(1955)$.

14. Sturgeon, P., And Arcilla, M. B.: Studies on the secretion of blood group substances. I. Observations on the red cell phenotype Le $(a+b+x+)$. Vox Sang., 18: 301 (1970).

15. Turowska, B., AND Bromboszcz, A.: Cited by Harper et al. [5]: ABH secretor status of the fetus: a genetic marker identifiable by amniocentesis. J. Med. Genet., $s: 438$ (1971).

16. Watkins, W. M.: Biochemical and genetical aspects of bloodgroup specificity. XXIst John G. Gibson II Lecture, New York (1968).

17. This investigation was supported by United States Public Health Service Research Grant no. HL 11160 from the National Heart and Lung Institute, National Institutes of Health, Bethesda, Maryland.

18. Requests for reprints should be addressed to: MiNERVA B. Arculla, M.D., Gwynne Hazen Cherry Memorial Laboratories, Department of Pediatrics, Hematology Division, University of California at Los Angeles School of Medicine, Los Angeles, Calif. 90024 (USA).

19. Accepted for publication August 21, 1972. 